\title{
Microarray Analysis Shows That Recessive Resistance to Watermelon mosaic virus in Melon Is Associated with the Induction of Defense Response Genes
}

\author{
Daniel Gonzalez-Ibeas, ${ }^{1}$ Joaquin Cañizares, ${ }^{2}$ and Miguel A. Aranda ${ }^{1}$ \\ ${ }^{1}$ Departamento de Biología del Estrés y Patología Vegetal, Centro de Edafología y Biología Aplicada del Segura (CEBAS)- \\ CSIC, apdo. correos 164, 30100 Espinardo (Murcia), Spain; ${ }^{2}$ Instituto de Conservación y Mejora de la Agrodiversidad \\ Valenciana (COMAV)-UPV, Camino de Vera s/n, 46022 Valencia, Spain
}

Submitted 19 July 2011. Accepted 12 September 2011.

\begin{abstract}
Resistance to Watermelon mosaic virus (WMV) in melon (Cucumis melo L.) accession TGR-1551 is characterized by a significant reduction in virus titer, and is inherited as a recessive, loss-of-susceptibility allele. We measured virus RNA accumulation in TGR-1551 plants and a susceptible control ('Tendral') by real-time quantitative polymerase chain reaction, and also profiled the expression of 17,443 unigenes represented on a melon microarray over a 15-day time course. The virus accumulated to higher levels in cotyledons of the resistant variety up to 9 days postinoculation (dpi) but, thereafter, levels increased in the susceptible variety while those in the resistant variety declined. Microarray experiments looking at the early response to infection ( 1 and $3 \mathrm{dpi}$ ), as well as responses after 7 and 15 dpi, revealed more profound transcriptomic changes in resistant plants than susceptible ones. The gene expression profiles revealed deep and extensive transcriptome remodeling in TGR-1551 plants, often involving genes with pathogen response functions. Overall, our data suggested that resistance to WMV in TGR-1551 melon plants is associated with a defense response, which contrasts with the recessive nature of the resistance trait.
\end{abstract}

Virus resistance in plants may involve the activation of a resistance response, the inhibition of virus functions, or the loss of virus susceptibility. Dominant resistance is normally associated with the activation of resistance responses (Marathe et al. 2004), although specific examples involve the inhibition of a viral function (Ishibashi et al. 2007). In contrast, recessive resistance is usually associated with the loss of susceptibility (Truniger and Aranda 2009). Several cultivar-specific recessive resistance genes have been cloned and characterized, showing that they encode eukaryotic translation initiation factors (eIF) of the 4E and 4G families (Robaglia and Caranta 2006; Truniger and Aranda 2009). Where resistance mechanisms have been dissected in detail, and it has been shown that recessive alleles are unable to provide a complementary function for the virus. For example, the eIF4E ${ }^{\mathrm{Leu} 228}$ protein encoded by the melon $n s v$ resistance gene is unable to complement the cap-independent translational initiation of Melon necrotic spot virus RNAs

Corresponding author: M. A. Aranda; Telephone: +34-968396355. Fax: +34-968396213; E-mail address: m.aranda@cebas.csic.es

* The $e$-Xtra logo stands for "electronic extra" and indicates that four supplementary figures and two supplementary tables are published online.
(Nieto et al. 2006; Truniger et al. 2008). However, the characterization of artificially induced mutants has shown that not all loss-of-susceptibility alleles correspond to eIF4E or eIF4G genes and, therefore, that other recessive virus-resistance genes may exist (Truniger and Aranda 2009). The characterization of these resistance genes and their corresponding mechanisms may provide insight into undiscovered biological processes that confer virus resistance in plants. In the absence of a complete molecular characterization of such resistance genes, the comparative analysis of diverse physiological characteristics in virus-inoculated susceptible and resistant plants might shed light on the resistance mechanisms (Palukaitis and Carr 2008).

Viruses affect the physiology and metabolism of infected plants, and this can be monitored by looking for changes in host gene expression profiles that are either directly or indirectly influenced by viral infection (Aranda et al. 1996; Maule et al. 2002; Wang and Maule 1995). With the advent of highthroughput technologies such as expressed sequence tags (EST), microarrays, and next-generation sequencing, it has become feasible to provide functional data for many genes simultaneously and to study the remodeling of the plant transcriptome in response to virus infections (Whitham et al. 2006). Over the last 10 years, DNA microarrays have become a popular strategy for comparative high-throughput gene expression analysis. The results of more than 500,000 experiments have been deposited in the Gene Expression Omnibus database (GEO) (Barrett et al. 2011), and many tools are available for mining the data (Dudoit et al. 2003; Page and Coulibaly 2008).

Microarrays have been used to monitor changes in the transcriptome in response to virus infections in both compatible (Golem and Culver 2003; Senthil et al. 2005; Whitham et al. 2003) and incompatible (Marathe et al. 2004) interactions. This strategy has focused on commercially important crops such as grapevine (Espinoza et al. 2007), citrus fruit (Gandía et al. 2007), potato (Gammelgård 2007; Pompe-Novak et al. 2005), rice (Satoh et al. 2010), populus (Smith et al. 2004), maize (Shi et al. 2005), soybean (Babu et al. 2008), and tomato (Catoni et al. 2009). The relative scarcity of genomic data for melon has made such an approach more challenging in this species but the number of available melon EST has increased considerably in the last 4 years (Clepet et al. 2011; Gonzalez-Ibeas et al. 2007). In the case of the Melogen database, more than 33,000 EST have been sequenced to generate approximately 17,000 tentative consensus sequences (unigenes) (Gonzalez-Ibeas et al. 2007). A publicly available database containing all EST, contig images, and several tools for data analysis and mining has been created, and the unigene sequences have been used to 
construct an oligo-based DNA microarray with a basic fourplex design and 75,000 probes. Each unigene is represented by four 60-mer probes, synthesized by photolithography, and designed according to quality rules based on uniqueness (nonredundancy), frequency in the transcriptome and melting temperature. This platform has been validated and used to analyze fruit quality traits, ovary development, and pathogen infections (Mascarell-Creus et al. 2009).

Here, we describe microarray experiments involving 17,443 unigenes represented on the melon microarray, which reveal extensive remodeling of the melon transcriptome in resistant and susceptible genotypes in response to infection with Watermelon mosaic virus (WMV) (genus Potyvirus, family Potyviridae). The resistant TGR-1551 accession is either asymptomatic or exhibits mild disease symptoms following mechanical inoculation with WMV, whereas susceptible cultivars show severe mosaic symptoms in systemically infected leaves. Infected TGR-1551 plants also have a substantially lower virus titer than susceptible controls (Diaz-Pendon et al. 2005). The inheritance of the resistance trait is thought to be controlled by a recessive allele, perhaps in combination with an epistatic interaction at a second locus (Diaz-Pendon et al. 2005). We describe the differentially expressed unigenes revealed by the microarray experiments and their relevance in terms of the observed physiological responses to infection, and discuss potential mechanisms controlling TRG1551 resistance to WMV.

\section{RESULTS}

\section{Accumulation of virus RNA in resistant and susceptible melon plants inoculated with WMV.}

The progress of WMV infection in the resistant accession TGR-1551 and the susceptible 'Tendral' was determined by comparing the accumulation of WMV RNA by real-time quantitative polymerase chain reaction (qPCR) in inoculated cotyledons at different times after inoculation, and in systemically infected leaves. WMV accumulated to higher levels in TGR-1551 cotyledons up to 9 days postinoculation (dpi) but the situation had reversed by 15 dpi (Fig. 1A). In the systemically infected second true leaf, WMV accumulated to much higher levels in 'Tendral' than TGR-1551 by 15 dpi (Fig. 1A). No symptoms were evident in the cotyledons of either genotype or in systemically infected TGR-1551 leaves, whereas severe symptoms were observed in infected 'Tendral' leaves, including mosaics, vein banding, leaf bubbling or malformation, and growth stunting (Fig. 1B). These results confirmed previous observations (DiazPendon et al. 2005) and showed that TGR-1551 resistance to WMV manifests as a significant virus titer reduction in systemically infected leaves accompanied by an almost complete absence of symptoms. For the transcriptomic analysis described below, we used samples from inoculated cotyledons at 1 and 3 dpi to monitor early changes in response to virus infection, and samples from inoculated cotyledons at $7 \mathrm{dpi}$ because, at this time, there was a significant difference in virus accumulation between the genotypes, completing a temporal window with three time points. In addition, samples from systemically infected leaves at 15 dpi were also included in the analysis (Fig. 1A).

\section{Construction of microarray expression data sets, sources of variability, and the amplitude of deregulation.}

We used a previously validated melon microarray (MascarellCreus et al. 2009) to carry out 36 hybridizations on cotyledon samples (two genotypes $\times$ two treatments $\times$ three sampling times $\times$ three biological replicates) and 12 for leaf samples (two genotypes $\times$ two treatments $\times$ three biological replicates). Microarray hybridization images were reconstructed for visual inspection using raw expression data and we did not detect artifacts such as scratches, bubbles, or high local or overall background. Expression data were normalized as previously described (Mascarell-Creus et al. 2009).

In order to characterize the global biological variability among samples, normalized data were processed by principal component analysis (PCA). Cotyledon samples were primarily grouped by genotype (TGR-1551 versus 'Tendral') and then by days postinoculation. No obvious association was found among infected versus mock-inoculated samples, except perhaps for TGR-1551 cotyledons at 3 and 7 dpi (Fig. 2A). Therefore, transcriptomic alterations over time or genotype appeared to be more important than alterations associated with viral infection in inoculated cotyledons. Intriguingly, more dispersion was observed in the TGR-1551 samples, particularly the mock inoculations. Indeed, three of them were considered outliers and, therefore, were excluded from further analysis. To use the same criterion for both genotypes, three mock-inoculated cotyledon samples from each of the three time points were also excluded from the analysis, reducing the group of samples used for further analysis to three biological replicates for infected samples and two biological replicates for mock-inoculated cotyledons. Infected versus mock-inoculated leaves in each principal group showed limited differentiation in 'Tendral' samples but extensive differentiation in TGR-1551 samples, suggesting a significant transcriptomic impact in leaves of the resistant genotype where a clear differentiation among infected versus mock-inoculated samples was observed (Fig. 2B). Higher variability was found among the 'Tendral' biological replicates. To confirm these PCA results, a hierarchical clustering analysis was performed on the samples using the expression data after normalization (Fig. 2C and D). In cotyledon samples, principal clusters were identified first by genotype. In agreement with the PCA results, 'Tendral' samples grouped first by time instead of the presence or absence of infection, confirming that transcriptomic variation over time was more important than the response to infection in this genotype. In contrast, TGR-1551 cotyledon samples from 3 and $7 \mathrm{dpi}$ grouped depending on whether or not they were infected (Fig. 2C). In conclusion, transcriptomic remodeling due to WMV infection appears to have more profound effects in TGR-1551 than in 'Tendral' cotyledons, a phenomenon much more pronounced in the leaf samples where small transcriptomic changes and replicate dispersion in 'Tendral' led to mixed clustering of mock-inoculated and infected samples (Fig. 2D).

\section{Genes differentially expressed in inoculated cotyledons.}

Differentially expressed unigenes in cotyledons were identified using microarray significant profiles (MaSigPro) (Conesa et al. 2006). The MaSigPro program is based on regression model approaches and is a good alternative to classical methods based on $t$ tests, such as significance analysis of microarrays (SAM) (Tusher et al. 2001) or analysis of variance-based methods (Park et al. 2003), for the analysis of time course microarray series. This is because regression-based methods are considered more effective for capturing the dynamic nature of time course data (Conesa et al. 2006). Using time as a continuous variable and a false discovery rate (FDR) of $0.01(1 \%)$, we found that 3,291 unigenes (Supplementary Table 1) were differentially expressed in infected 'Tendral' samples relative to mock-inoculated controls, whereas 2,488 unigenes were differentially expressed in infected TGR-1551 samples. We found that 677 unigenes were deregulated in both genotypes. Samples were clustered based on the expression of deregulated unigenes, showing that they grouped first by days postinoculation and then by infection status (Fig. 3A), specially in 'Tendral'. In the case of TGR1551, samples clustered depending on whether or not they were infected, probably due to the bigger transcriptomic alterations 
consequence of the infection observed in this genotype (Fig. 2A, PCA analysis). Box-plot diagrams showing the fold changes of deregulated unigenes indicated that the amplitude of deregulation was greater in the resistant than the susceptible genotype (Fig. 4).

We next identified functional categories that were over-represented in deregulated unigenes using the Gene Ontology (GO) (Ashburner et al. 2000) vocabulary. The results are summarized in Figure 5 with a set of nonredundant GO categories, whereas a complete list is provided in Supplementary Fig. S1. In TGR-1551, the GO terms "chloroplast thylakoid lumen" and "cellulose and pectin-containing cell wall" were over-represented in deregulated unigenes, whereas "ribosome biogenesis and assembly" and "translation" were under-represented. In contrast, several GO terms related to translation were over-rep- resented among the deregulated unigenes in 'Tendral', whereas chloroplast-related GO terms were under-represented. When the 677 unigenes that were deregulated by WMV infection in both genotypes were used to search statistically significant GO terms, the categories "chromatin assembly" and localization in the "endomembrane system" were identified (data not shown).

We performed additional analysis using viral load as a continuous variable instead of time in the regression model because the kinetics of viral RNA accumulation was different in both melon genotypes and, at $7 \mathrm{dpi}$, there was a significant difference in virus accumulation (Fig. 1A). In this new analysis, using an FDR of 0.05 (5\%), 77 unigenes were found to be differentially expressed in 'Tendral' and 111 in TGR-1551, and only 3 were common to both genotypes. Based on expression data, samples were clustered in this case first by infection
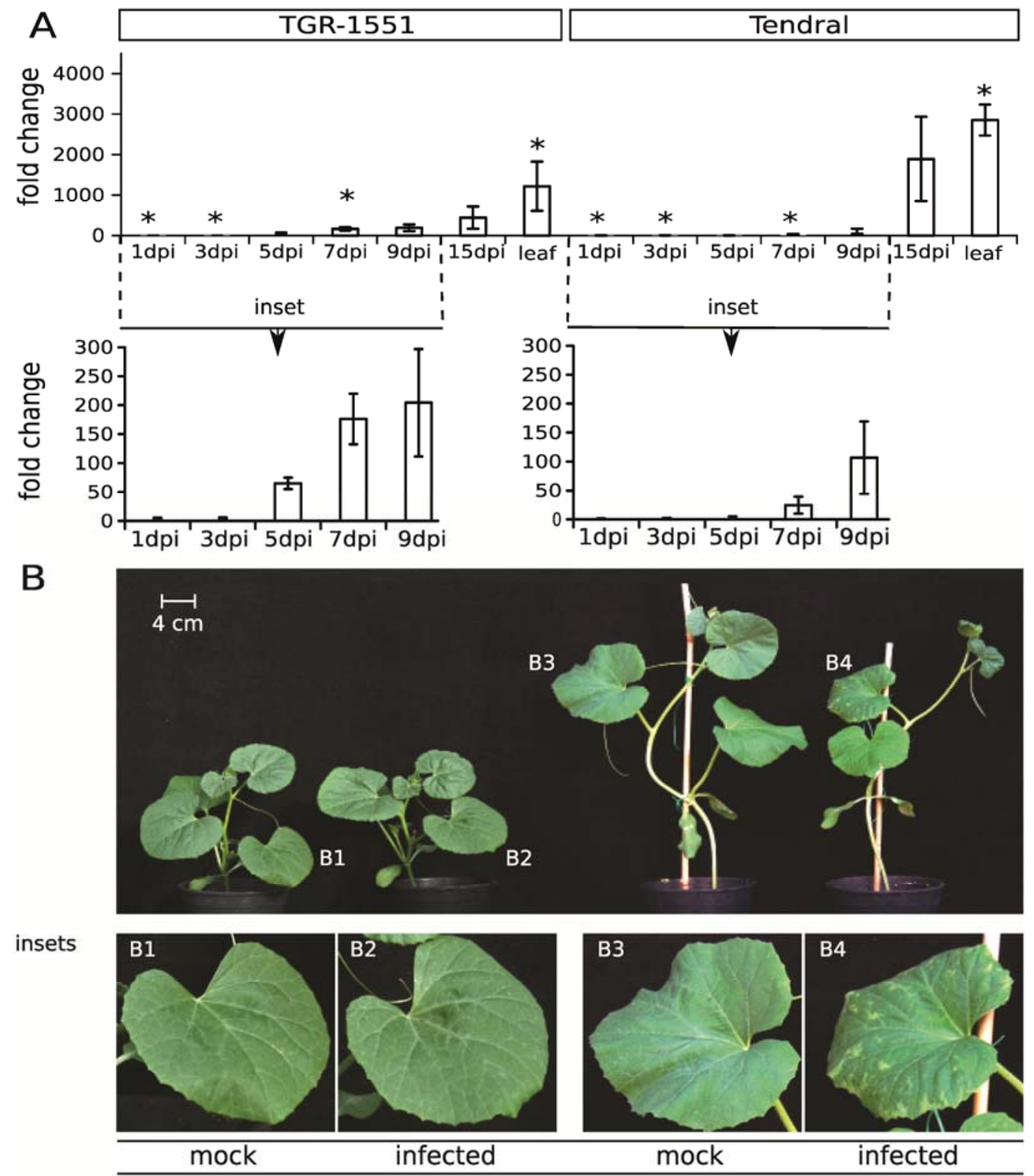

Fig. 1. Viral load and symptoms in melon plants infected with Watermelon mosaic virus (WMV). A, Pattern of RNA accumulation in 'Tendral' (susceptible) and TGR-1551 (resistant) plants as measured by quantitative polymerase chain reaction. Infected samples at 1 day postinoculation (dpi) were used as calibrators for relative quantification. Samples from inoculated cotyledons were harvested from 1 to 15 dpi, and the systemically infected second true leaf was harvested at 15 dpi. Biological replicates of pooled RNA samples (two in the case of mock-inoculated cotyledons, four in the case of infected cotyledons, and three in the case of leaf samples) were used for each days postinoculation-genotype combination. Asterisks show the samples selected for microarray hybridizations. RNA accumulation in samples at early stages ( 1 to 9 dpi) is shown in the insets at a different scale. B, Melon plants used for this analysis. Second true leaves of healthy and virus-infected plants from each genotype are shown in the insets: B1, mock-inoculated TGR-1551 plant; B2, WMVinfected TGR-1551 plant; B3, mock-inoculated Tendral plant; B4, WMV-infected Tendral plant. 
status and then by days postinoculation (Fig. 3B). Interestingly, infected samples at 7 dpi grouped more independently relative to the other samples in both genotypes. No significantly deregulated GO terms were found in the corresponding sets of unigenes. Manual inspection of the unigene annotations identified transcripts encoding proteins located in the endomembrane system and unigenes coding for methyltransferases, enzymes related to fatty acid metabolism (some of them localized in chloroplasts), a copper-binding protein (laccase), peroxidases, a pyruvate kinase, WRKY transcription factors and, glucanases.

\section{Genes differentially expressed}

\section{in systemically infected leaves.}

Deregulated genes in leaves were identified using SAM (Tusher et al. 2001). Much more biological variability was found in 'Tendral' compared with TGR-1551 replicates; therefore, differentially expressed unigenes were identified at different levels of confidence for each genotype. Using an FDR of $1 \%, 1,886$ deregulated unigenes were identified in the resistant genotype, whereas only 121 unigenes were found in the susceptible genotype even with an FDR of 19\%, strongly suggesting more profound transcriptome remodeling in the resistant genotype. Box-plot diagrams (Fig. 4B) revealed that, in addition to the number of deregulated unigenes, the amplitude of deregulation was also higher in TRG-1551 leaves. Up to 30 unigenes were deregulated in both genotypes.

The GO categories over-represented in these sets of unigenes are summarized in Figure 6. In 'Tendral', no significant terms were identified among the 22 downregulated unigenes and, among the 99 upregulated genes, the most abundant transcripts were those related to toxin metabolic processes, the response to salicylic acid stimulation, and glutathione transferase activity (Fig. 6). In TGR-1551, GO terms related to biotic stimuli and responses to other organisms were over-represented among the deregulated unigenes, mainly reflecting the accumulation of transcripts involved in pathogen defense (e.g., WRKY and MYB transcription factors, and pathogenesis-related [PR]like proteins) and stress responses (e.g., peroxidases, lipoxigenases, and heat-shock proteins) (Fig. 6). Cytoskeleton-related unigenes were downregulated in both genotypes, albeit with a

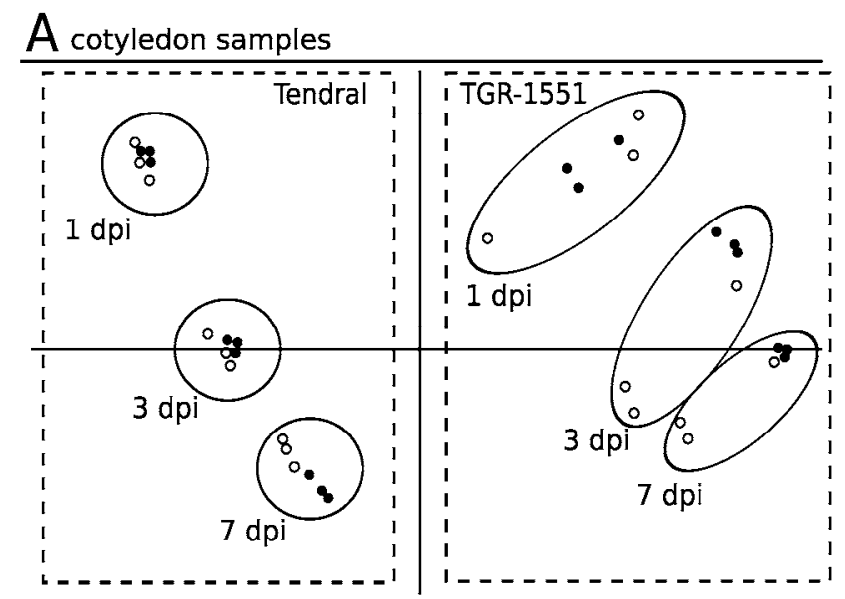

C cotyledon samples

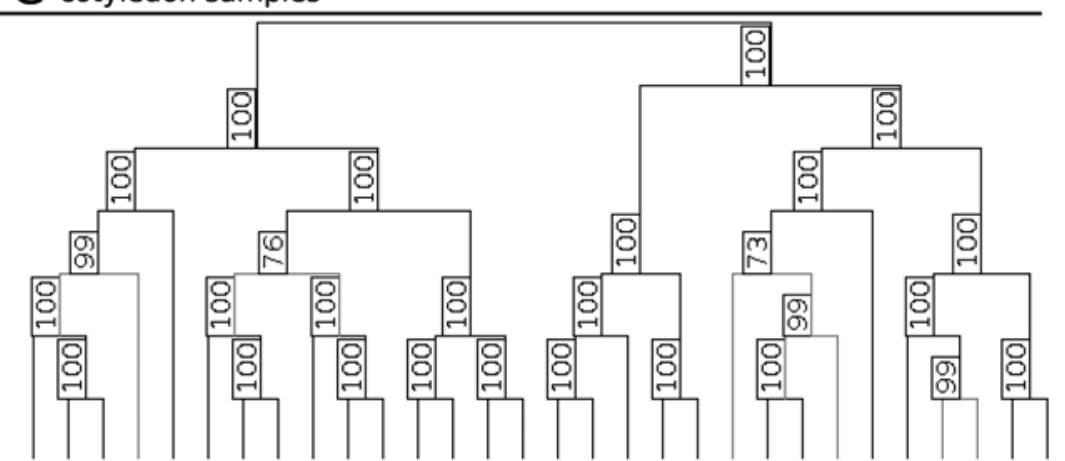

हᄐ

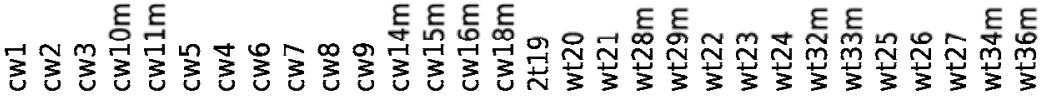

- $00 . \bullet \cdot 0000100$

TGR-1551

genotype

dpi

\begin{tabular}{|l|l|l|l|l|l||c|c|}
\hline \multicolumn{3}{|c|}{ TGR-1551 } & \multicolumn{3}{|c|}{ Tendral } \\
\hline \hline 1 & 3 & 7 & 3 & 7 & 1 & 3 & 7 \\
\hline
\end{tabular}

B leaf samples

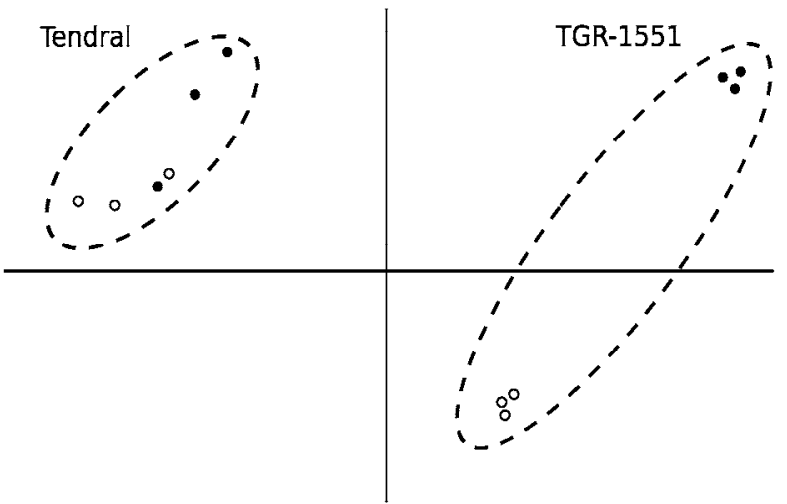

D leaf samples
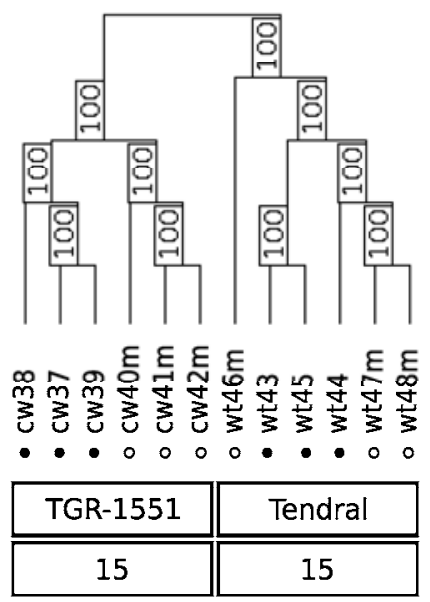

o mock inoculated sample virus infected sample dpi = days postinoculation

Fig. 2. Analysis of biological variability in microarray samples. A, Principal component analysis (PCA) of cotyledon samples at 1,3 , and 7 days postinoculation (dpi) for the TGR-1551 (resistant) and 'Tendral' (susceptible) melon genotypes analyzed after normalization by microarray. Dashed lines: samples grouped by genotype. Black continuous lines: samples grouped by days postinoculation. B, PCA for leaf samples. Dashed lines: samples grouped by genotype. C, Dendrogram obtained after bootstrapped clustering of cotyledon samples. D, Dendrogram obtained after bootstrapped clustering of leaf samples. 
greater amplitude in TGR-1551. The exception was unigene cA_15-G12-M13R_c, which is related to microtubule-associated protein RP/EB. This was upregulated strongly in the resistant genotype but downregulated in susceptible plants. Heatshock proteins were strongly upregulated in TGR-1551 leaves but appeared unaffected in 'Tendral' plants. In contrast, DNAJlike proteins, which are also involved in protein folding, were downregulated in TGR-1551 leaves. These data provide evidence of a complex resistance response in TGR-1551 leaves following WMV infection.
Expression profiles

of defense, stress and endomembrane system genes.

We compared the expression profiles of differentially expressed unigenes in the leaves and cotyledons of both genotypes. Many of the unigenes that were deregulated in leaves were also deregulated in cotyledons, suggesting similar underlying processes in both tissues. For example, unigenes encoding proteins involved in phytohormone biosynthesis and signaling (gibberellins, auxins, and cytokinins) followed this general trend (data not shown). Similarly, more than 150 unigenes re-
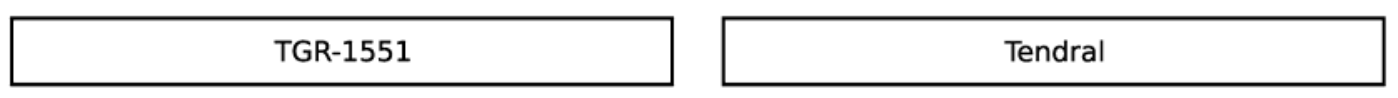

A

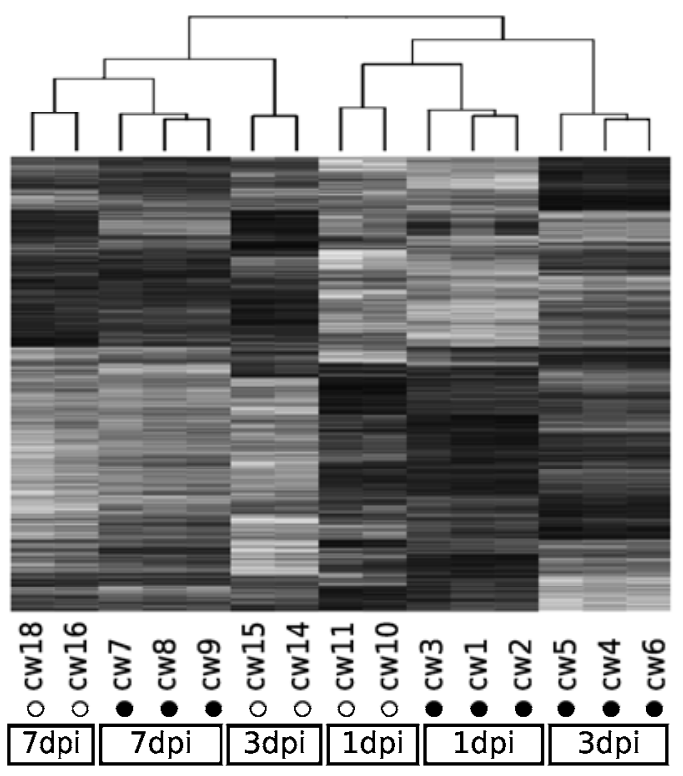

B
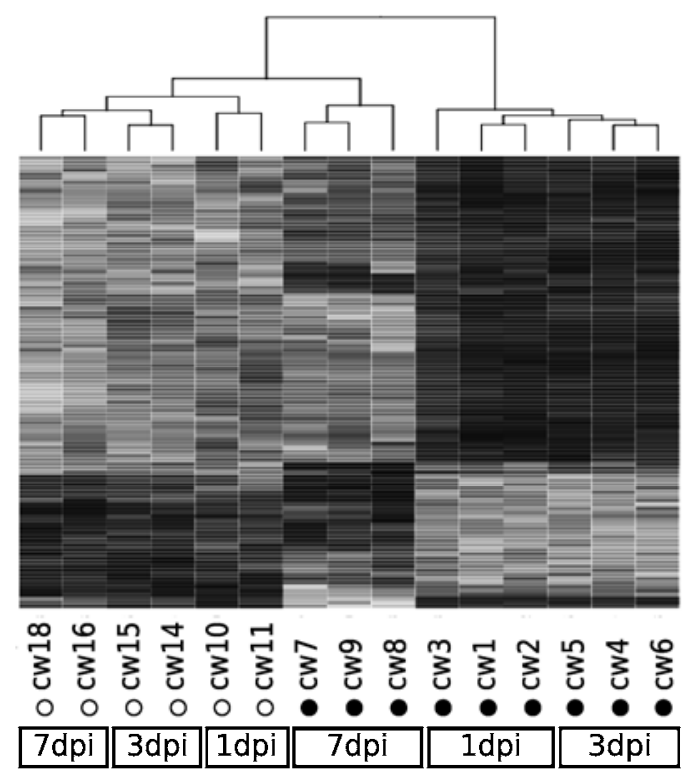

o mock inoculated

- infected sample

$\mathrm{dpi}=$ days postinoculation
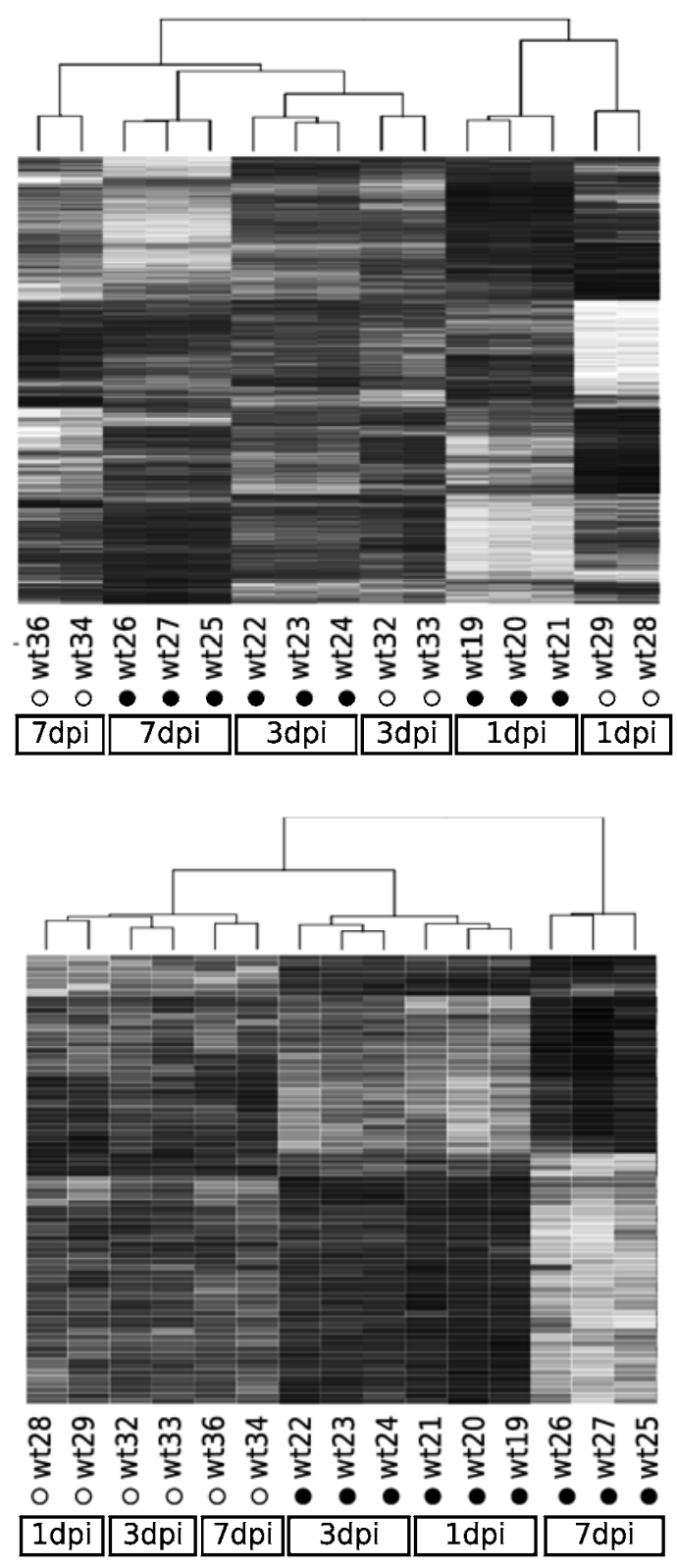

gene expression level (microarray signal intensity)

low level

high level

Fig. 3. Cluster analysis of samples based on identified deregulated unigenes. Expression image of significant differentially expressed unigenes identified using the microarray significant profile $\mathrm{R}$ package by using $\mathbf{A}$, time or $\mathbf{B}$, viral load as the continuous variable. Samples used for microarray hybridizations were clustered based on the expression of these deregulated unigenes and the dendrogram is shown for each genotype. 
lated to endomembrane system functions were strongly deregulated in TGR-1551 leaves and cotyledons, and deregulated to a lesser extent in the 'Tendral' genotype.

Several transcripts with defense and stress-response functions showed differential accumulation profiles among the four genotype-tissue combinations, although a similar pattern emerged with stronger deregulation in TGR-1551 than 'Tendral'. The expression profiles of selected unigenes are shown in Figure 7, and profiles of sets of unigenes grouped by functional annotation are shown in Supplementary Figure S2. Unigenes in the "response to oxidative stress" category, especially peroxidases, were the most abundant. They were strongly deregulated in TGR-1551 leaves, weakly deregulated in 'Tendral' leaves, and moderately deregulated in the cotyledons of both genotypes. They also showed different expression dynamics, maintaining induction until $7 \mathrm{dpi}$ in TGR-1551 but peaking at $1 \mathrm{dpi}$ and declining thereafter in 'Tendral' plants; for example, unigene cAI_14A12-M13R_c (Fig. 7). Unigenes annotated with the GO term "response to other organisms" (most of them lipoxigenases) were clearly upregulated in TGR-1551 leaves but were not affected or downregulated in 'Tendral' leaves and cotyledons; for example, unigene cPSI_25-A03-M13R_c (Fig. 7). MYB transcription factors were preferentially upregulated in TGR1551 leaves and showed stronger deregulation in TGR-1551 cotyledons compared with 'Tendral', in some cases with opposite trends; for example, unigene cAI_15-F09-M13R_c (Fig. 7).

cotyledon samples
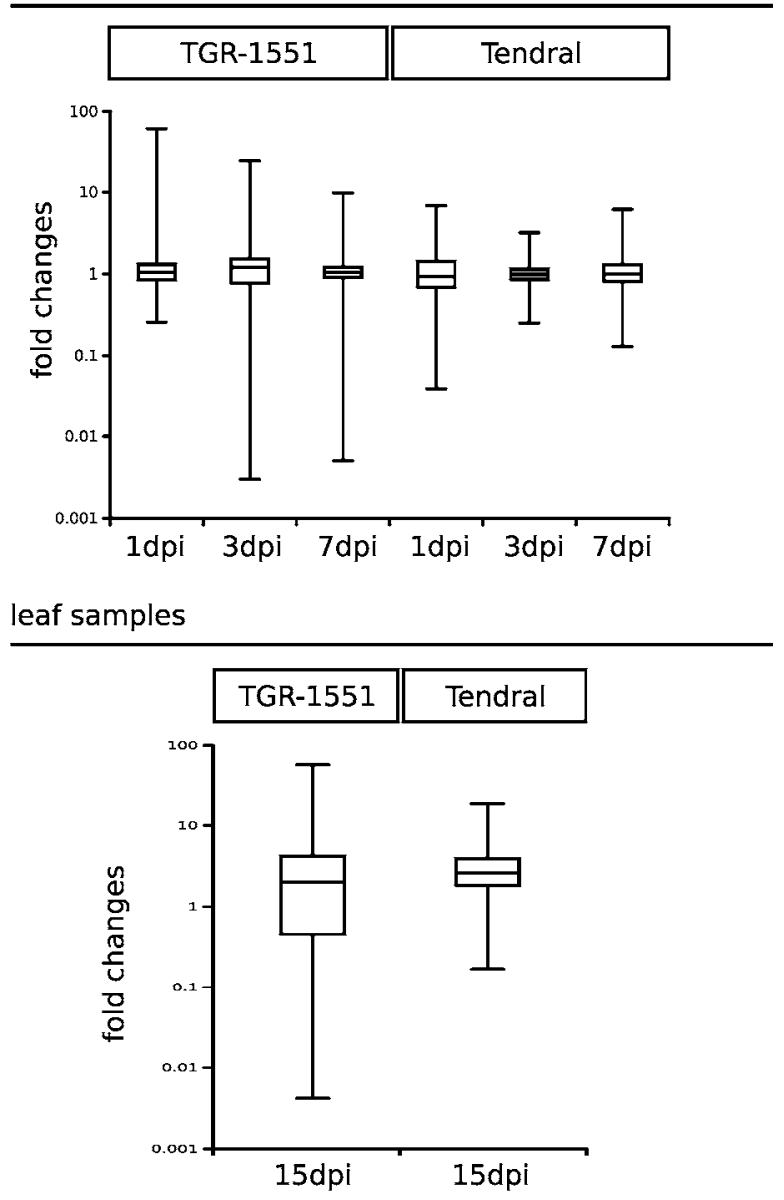

Fig. 4. Broad gene expression trends in samples analyzed by microarray. Gene expression fold changes were calculated for deregulated unigenes identified by microarray analysis and used to construct box plots for each genotype-tissue-days postinoculation (dpi) combination. Results are shown for cotyledon and leaf samples.
Several PR-like proteins were upregulated in TGR-1551 and 'Tendral' leaves, in principle with similar amplitudes but potentially with higher intensities in TGR-1551 due to microarray signal saturation effects (see below and Discussion). Similarly, chitinases, glutathione-S-transferases, and WRKY transcription factors were also deregulated in leaves of both genotypes but different accumulation dynamics were observed in cotyledons, showing stronger deregulation in TGR-1551; for example, unigene cAI_21-H01-M13R_c (Fig. 7). Germin-like proteins annotated with the "apoplast" GO term, dirigent-like proteins, and syntaxins were more strongly upregulated in TGR-1551 leaves than 'Tendral' leaves but also deregulated in cotyledons. Several UDP-glucosyltransferases were upregulated in TGR-1551 leaves but not deregulated in 'Tendral' leaves. In contrast, unigenes encoding phenylalanine ammonia lyase were upregulated in 'Tendral' leaves but not deregulated in TRG-1551 leaves. Other transcripts, such as those annotated as nucleotide-binding site leucine-rich repeat proteins, showed weak deregulation in both tissues of both genotypes. These data support the induction of a complex resistance response in TGR-1551 plants following WMV infection.

\section{Microarray data validation by real-time qPCR.}

We validated the microarray expression data by using realtime qPCR to measure the accumulation of five melon transcripts in the samples used for microarray hybridizations. We chose transcripts encoding HSP17.6, two PR proteins, a calmodulin-binding protein, and a chitinase A, all potentially involved in pathogenesis (Table 1). In total, 210 expression values (150 from cotyledons and 60 from leaves) from both microarray and qPCR experiments were analyzed, the fold changes were calculated, and expression patterns were compared (Supplementary Fig. S3). In cotyledon samples, the qPCR data for four of the transcripts matched the differential trends between the genotypes observed in the microarray experiments. The exception was unigene MU10940 at 3 dpi in TGR-1551, which showed lower variation than was apparent from the microarray data. In leaf samples, different trends were observed for each genotype, with 'Tendral' samples showing good correlation in tendency and amplitude but TGR-1551 samples showing a correlation in tendency but not in amplitude (qPCR indicated higher fold changes than the microarray data). However, the expression profiles of the five transcripts were mostly coincident, with Pearson correlation coefficients ranging from 0.75 to 0.96 (Table 1 ).

\section{DISCUSSION}

Microarray analysis has been widely used to compare the transcriptomes of virus-infected plants and healthy controls (Agudelo-Romero et al. 2008; Babu et al. 2008; Catoni et al. 2009; Dardick 2007; Espinoza et al. 2007; Gandía et al. 2007; Golem and Culver 2003; Pompe-Novak et al. 2005; Satoh et al. 2009; Senthil et al. 2005; Smith et al. 2004; Whitham et al. 2003). However, few of these studies have focused on incompatible plant-virus interactions with the intention of gaining information about resistance mechanisms (Gammelgård 2007; Marathe et al. 2004; Shi et al. 2005). We used microarrays to study TGR-1551 resistance to WMV by comparing transcriptome responses in this accession and a susceptible variety.

\section{Differentially expressed unigenes.}

Over 3,000 differentially expressed unigenes were identified in cotyledons when time was used as a continuous variable in the MaSigPro program. Clustering based on expression data showed that the samples grouped preferentially by days postinoculation for every genotype, suggesting that the large 
number of deregulated unigenes represented transcriptomic changes over time rather than in response to infection. We attribute this result to the slow progression of the WMV infection, characteristic of Potyvirus spp., as noted by the low level of WMV RNA accumulation until 9 dpi (Fig. 1). This phenomenon was also genotype dependent, because larger transcriptome remodeling was found at early stages in cotyledons of the resistant genotype. However, for both genotypes, a manual inspection of the expression patterns after clustering (data not shown) revealed that many of the genes follow similar trends in healthy and infected samples. Therefore, a significant number of the deregulated unigenes expressed in cotyledons may represent false positives (i.e., their modulation may be incorrectly attributed to the infection). This may partially reflect the low biological dispersion observed among replicates, combined with the relatively small variations in expression observed in cotyledons.

In contrast, when the analysis was carried out using viral load as a continuous variable, only approximately 100 deregulated unigenes were identified for each genotype, in agreement with the PCA data. Samples clustered first by infection status and then by time, indicating that the new set of unigenes represented transcriptomic changes due to infection rather than the experimental time course. However, we believe that these experiments were complementary and that both have advantages and drawbacks. For example, many infection-related genes may also be modulated over time, making them impossible to identify when using viral load as continuous variable. The time course analysis could, for example, identify genes whose expression profile changes during the course of infection (e.g., in response to the increasing viral titer). Examples of such unigenes included type III homocysteine methyltranferases, laccases, enoyl-ACP reductases, calmodulin-binding proteins, peroxidases, and auxin response factors, many of them already known to be involved in plant-pathogen interactions (Abdel-
Ghany and Pilon 2008; Benschop et al. 2007; Chandra-Shekara et al. 2007; Raffaele et al. 2008).

\section{Mechanism of TGR-1551 resistance to WMV.}

TGR-1551 resistance to WMV may involve the restriction of virus movement (Diaz-Pendon et al. 2005), which would be compatible with both active and passive resistance mechanisms (Fraser 1992). If resistance were passive, as the recessive genetics would suggest, one should expect no activation of resistance responses in relation to appropriate controls. For example, functional genomics has been used to analyze potato resistance to Potato virus A (genus Potyvirus, family Potyviridae), which involves the inhibition of virus translocation from infected leaves. In this case, gene induction in resistant plants was only slightly greater than in susceptible ones (Gammelgård 2007). In contrast, our microarray results showed robust and distinct transcriptome remodeling in infected TGR-1551 plants, especially in leaf samples, involving many pathogen response transcripts. This indicated that a defense response associated with resistance is mounted in infected TGR-1551 plants.

How can this active resistance mechanism be reconciled with the recessive genetics of the resistance trait? One possible explanation is the absence or reduced expression of host factors that counteract resistance responses. Although such a mechanism has not yet been observed in virus infections, several cases can be cited for other pathogens. For example, recessive alleles generated by mutagenesis at the barley $M L O$ locus are responsible for wide-spectrum resistance to fungal pathogens (Büschges et al. 1997). There are 15 members of this protein family in Arabidopsis and, among seven homologous melon unigenes represented on our microarray, two were found to be deregulated. One was downregulated in 'Tendral' cotyledons at 1 dpi but was not deregulated in TGR-1551 cotyledons (data not shown), suggesting that 'Tendral' cotyledons

\begin{tabular}{l|lll} 
Go term name & P-value & Tendral \\
\hline
\end{tabular}
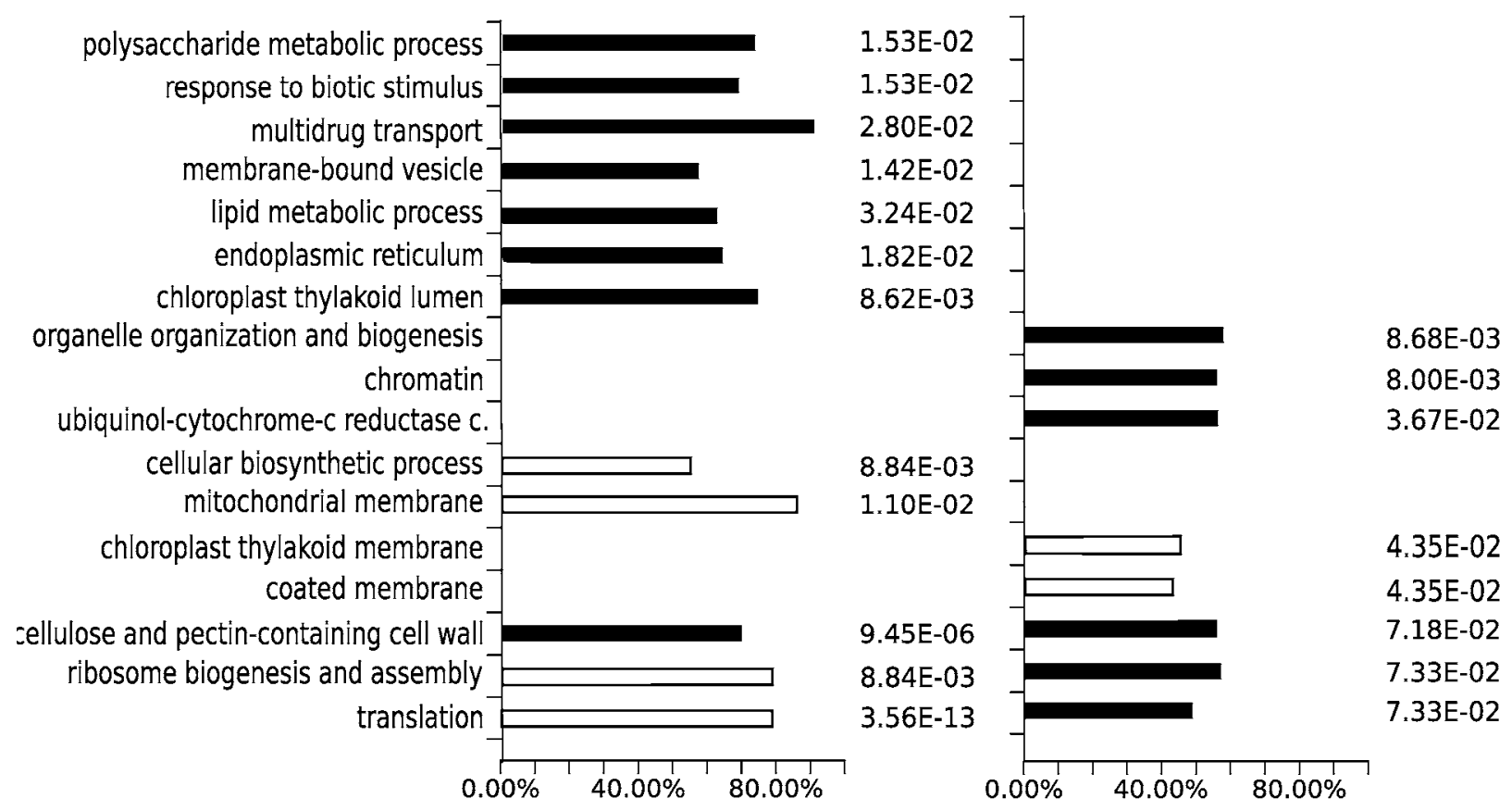

Fig. 5. Significant Gene 0ntology (GO) categories among the deregulated unigenes in cotyledons. Differentially expressed unigenes identified by the microarray analysis of cotyledon samples were used to analyze statistically significant GO terms, over-represented (black) and under-represented (white), for each genotype. Percentage of deregulated unigenes from the total number of unigenes included in each GO category is indicated on the horizontal axis. A selection of nonredundant categories is shown here. 
may attempt a defense response that is not initiated in TGR1551 plants. The other was downregulated in TGR-1551 leaves but not deregulated in 'Tendral' leaves, and this is an interesting candidate for further functional analysis. Other examples include Arabidopsis mutants with recessive alleles at the SSI2 (stearoyl-ACP desaturase) locus, which allow the constitutive accumulation of the transcript encoding PR-1 as well as salicylic acid, conferring resistance against bacteria, fungi, and Cucumber mosaic virus (Sekine et al. 2004). A melon transcript similar to a stearoyl-ACP desaturase was identified but its expression was strongly repressed at $7 \mathrm{dpi}$ in 'Tendral' plants and was not deregulated in TGR-1551 plants.

Genetic resistance to plant viruses often involves a small and highly conserved collection of genes (Kang et al. 2005; Truniger and Aranda 2009) (e.g., the eIF4E and eIF4G translational initiation factor genes involved in recessive resistance, especially to Potyvirus spp.) (Robaglia and Caranta 2006; Truniger and Aranda, 2009). Many cases of eIF4E-mediated resistance reflect a lack of virus multiplication at the cellular level. In some cases, however, eIF4E-mediated resistance still allows the systemic accumulation of virus particles, albeit to a lesser extent and without symptoms (Nicaise et al. 2003; Revers et al. 1997). This is similar to the situation in TGR-1551 plants infected with WMV but we did not identify any differentially expressed transcripts homologous to Arabidopsis eIF4E or eIF4G when comparing 'Tendral' and TGR-1551 plants (data not shown). Furthermore, sequencing eIF4E cDNAs and gene exons has not shown any difference between TGR-1551 and susceptible genotypes (Nieto et al. 2007). Even so, this hypothesis should not be completely ruled out because not all the translation initiation factors have been sequenced and characterized in TGR-1551, and there may be differences between transcript levels, protein levels, and protein activity that make mRNA profiling an unreliable indicator of the role of these proteins in resistance.

The resistance mechanism could also involve small RNAs. Recently, we screened the melon small RNome by pyrosequencing, and noted the differential accumulation of miR168,

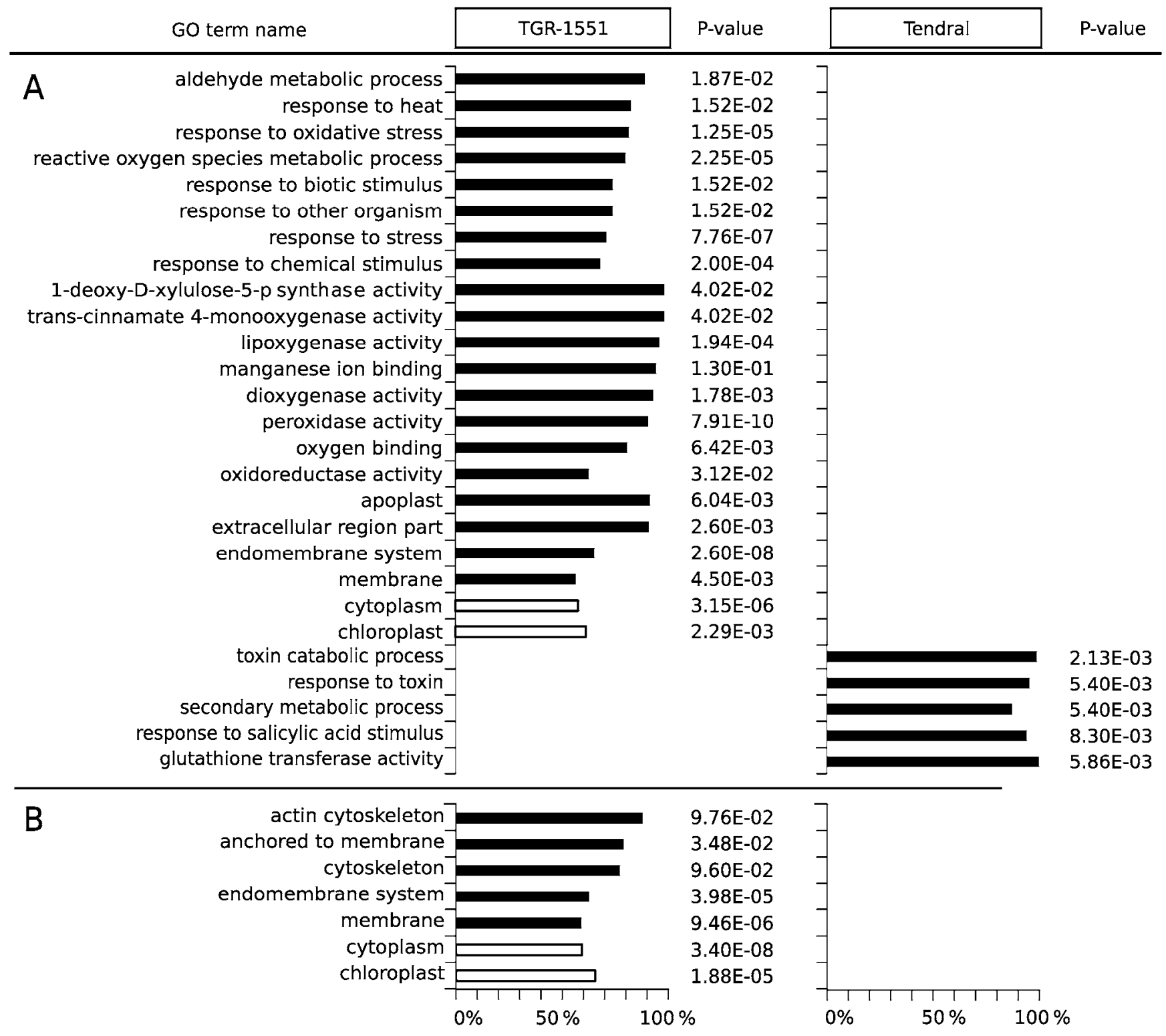

Fig. 6. Significant gene ontology (GO) categories among the deregulated unigenes in leaves. Differentially expressed unigenes identified by the microarray analysis of leaf samples were used to analyze statistically significant GO terms, over-represented (black) and under-represented (white), for each genotype. Percentage of deregulated unigenes from the total number of unigenes included in each GO category is indicated on the horizontal axis. A, Significant GO terms in upregulated unigenes and $\mathbf{B}$, significant GO terms in downregulated unigenes. 
which was expressed at high levels in TGR-1551 and at low levels in 'Tendral' (Gonzalez-Ibeas et al. 2011). This microRNA regulates the transcript for ARGONAUTE1 (AGO1), the catalytic subunit of the RNA-induced silencing complex responsible for post-transcriptional gene silencing (Vaucheret et al. 2006). Melon unigenes representing AGO proteins also showed differential trends between TGR-1551 and 'Tendral' in our microarray experiments, two in cotyledons and one in leaves. Interestingly, some melon unigenes annotated as transposons also showed different degrees of deregulation between the genotypes (i.e., strongly deregulated in TGR-1551 and not deregulated at all in 'Tendral'). Stress (including stress caused by pathogens) can modulate the transcriptional activity of transposons, and RNA interference can interfere with this pathway to activate transposable elements under non-stress conditions (Madlung and Comai 2004). The accumulation of miR168, the expression of the melon $A G O$ transcripts, and the expression of transposon unigenes may suggest the potential involvement of the silencing machinery in TGR-1551 resistance to WMV, although further work is required to investigate this hypothesis.
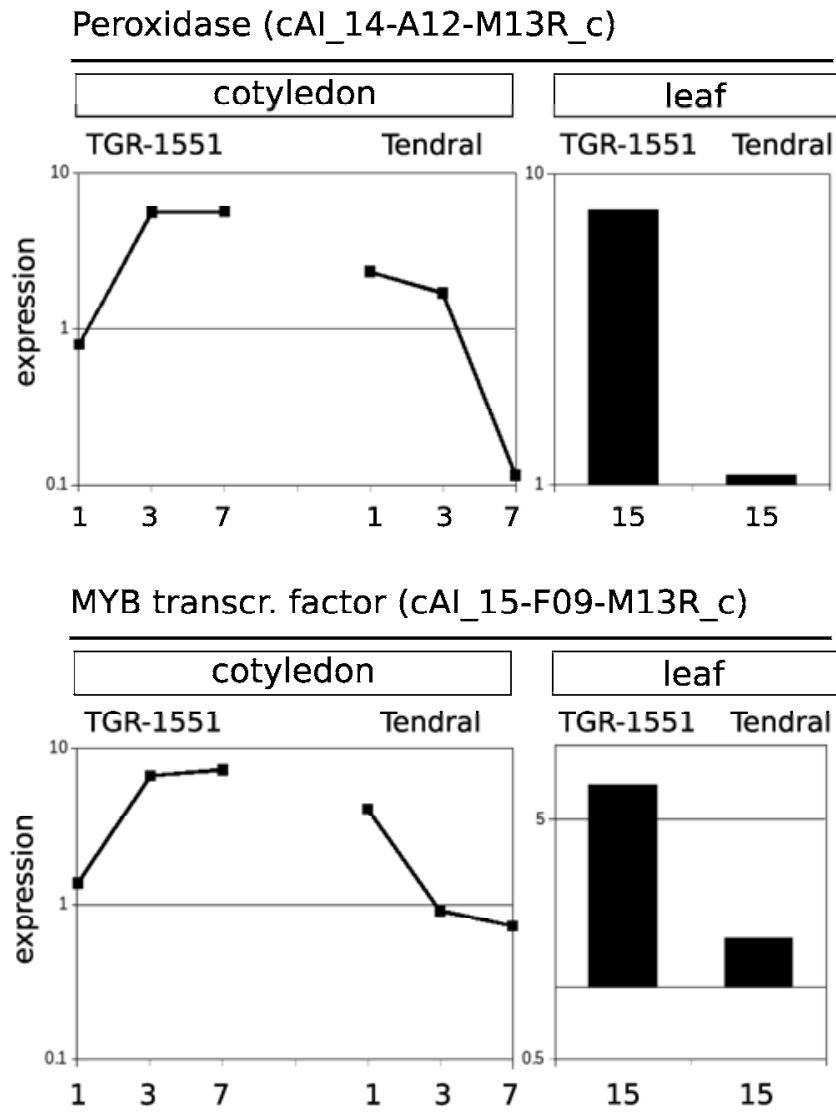

Validation of the microarray data showed a strong correlation between the qPCR and microarray datasets although, in TGR-1551 leaf samples, we noted that there was good correlation in the gene expression tendencies but not the amplitudes. Expression profiles often have a larger amplitude when detected by qPCR compared with microarray data (Dardick 2007; García-Marcos et al. 2009), and signal saturation effects for strongly expressed transcripts have also been observed when using microarrays (Lee 2004). The strongly expressed unigenes in TGR-1551 may reach this saturation limit, resulting in underestimated expression levels and therefore suggesting that transcriptomic variations in TGR-1551 leaves are greater than indicated by microarray hybridization, supporting the hypothesis that large-scale transcriptomic remodeling occurs in infected TGR-1551 plants. In addition to pathogen response transcripts, this robust transcriptome remodeling affected multiple metabolic processes and molecular functions. One interesting case was the deregulation of transcripts coding for ribosomal proteins. Ribosomes are key elements in the synthesis of proteins and there is evidence of different

\section{Lipoxigenase (cPSI_25-A03-M13R_c)}

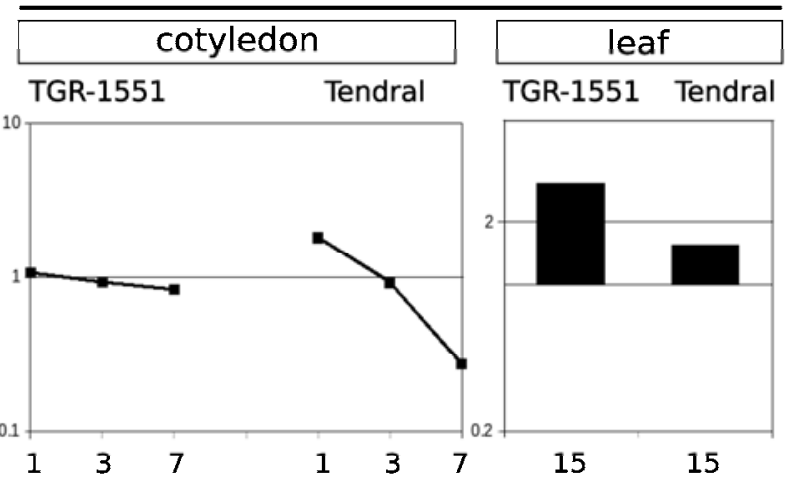

WRKY transcr. factor (CAI_21-H01-M13R_c)

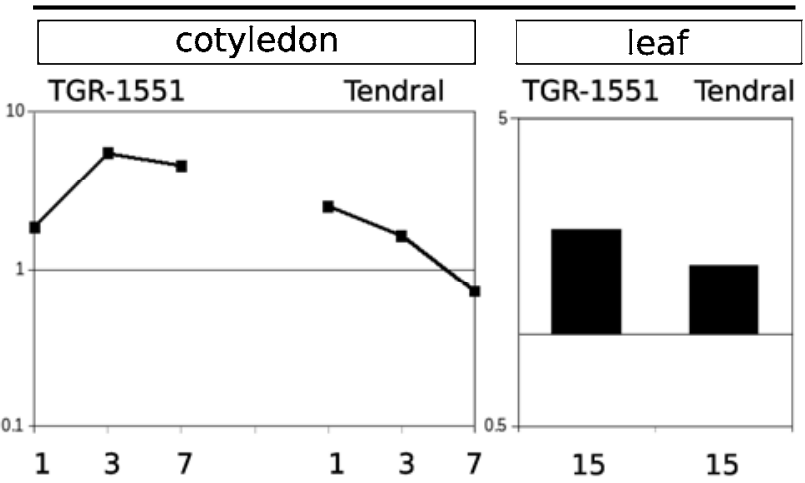

Fig. 7. Gene expression patterns of deregulated melon transcripts. For cotyledon samples, results are shown at 1, 3, and 7 days postinoculation (dpi) ( $x$ axis) For leaf samples, results are shown at $15 \mathrm{dpi}$ ( $x$ axis). Gene expression fold changes in infected samples relative to mock-inoculated controls are shown on the $y$ axis. Each unigene is named in parenthesis.

Table 1. Selected melon transcripts for microarray validation data by quantitative polymerase chain reaction

\begin{tabular}{|c|c|c|c|c|}
\hline Melon unigene $^{a}$ & $\begin{array}{l}\text { Arabidopsis } \\
\text { gene }\end{array}$ & Functional annotation & $\begin{array}{c}\text { Pearson } \\
\text { correlation } \\
\text { (cotyledon) }^{b}\end{array}$ & $\begin{array}{c}\text { Pearson } \\
\text { correlation } \\
{(\text { leaf })^{\mathbf{b}}}^{\text {pon }}\end{array}$ \\
\hline cCL5001Contig1 & AT1G53540 & 17.6-kDa class I small heat shock protein (HSP17.6C-CI) & 0.91 & 0.87 \\
\hline cCI_58-B08-M13R_c & AT3G04720 & Hevein-like protein (HEL); wound-induced protein WIN2 precursor & 0.96 & 0.89 \\
\hline cFR15P6_c & AT5G24090 & Acidic endochitinase (CHIB1) & 0.82 & 0.80 \\
\hline MU10940 & AT2G14610 & Pathogenesis-related protein (PR) & 0.87 & 0.75 \\
\hline cA_31-B03-M13R_c & AT3G13600 & Calmodulin-binding family protein & 0.84 & 0.80 \\
\hline
\end{tabular}

${ }^{a}$ Arabidopsis gene used for melon unigene annotation by sequence similarity.

${ }^{\mathrm{b}}$ Pearson coefficient correlation between microarray data and quantitative polymerase chain reaction results. 
ways to recruit them by viruses (Carroll et al. 2008; Doudna and Rath 2002). Recently, it has been described that ribosomal protein mRNAs show increased accumulation in Potyvirus infection of Arabidopsis, their induction is coordinated in response to infection, and several of them have been shown as cellular host factors required by some viruses for infection of Nicotiana benthamiana (Yang et al. 2007, 2009). Twentynine melon unigenes annotated as ribosomal proteins were found notoriously deregulated in leaves of TGR-1551 compared with 'Tendral' over the rest of ribosomal protein transcripts, which remained unaltered, suggesting specific deregulation and, perhaps, a potential role in the virus infection process. The same observation was extensive to other gene categories such as plant hormone metabolism, endoplasmic reticulum localization, or cell wall maintenance, revealing a deep adaptation of the plant physiology to the infection and highlighting microarrays, as broadly reported in many works, as powerful tools for identifying specific genetic elements involved in the process under study.

\section{MATERIALS AND METHODS}

Plant material, viral isolate, and virus inoculation.

Melon (Cucumis melo L.) accession TGR-1551 was originally collected in Zimbawe and shows resistance to WMV (Diaz-Pendon et al. 2005; Soria et al. 2003). TGR-1551 seed were kindly provided by Dr. Gómez-Guillamón (Estación Experimental "La Mayora"-CSIC, Málaga, Spain). 'Tendral' melon (Semillas Fitó, Barcelona, Spain) was used as the susceptible control. Seed were germinated in petri dishes for $48 \mathrm{~h}$ at $25^{\circ} \mathrm{C}$, and then sown in 0.5 -liter pots maintained in growth chambers (MLR-351H from Sanyo) with a 16-h photoperiod and 25 and $18^{\circ} \mathrm{C}$ day and night temperatures, respectively, for 3 weeks. Viral isolate WMV-M116 (Diaz-Pendon et al. 2005) was kindly provided by Dr. Moriones (Estación Experimental "La Mayora"-CSIC). Mechanical inoculations were carried out using standard procedures after the dehydrated viral inoculum was revived by mechanical inoculation of fully expanded squash cotyledons. Systemically infected squash leaves were harvested $15 \mathrm{dpi}$ and used as the inoculum for melon plants. The leaves were ground in a sterile mortar in the presence of inoculation buffer (0.2 M phosphate [ $\mathrm{pH} 8.0], 0.1 \%$ [vol/vol] $\beta$-mercaptoethanol, and active charcoal at $0.03 \mathrm{~g} / \mathrm{ml}$ ), mixed with 0.037-mm Carborundum particles, and dusted onto 7-dayold melon cotyledons. Control noninfected melon cotyledons were rubbed using the inoculation buffer alone (mock-inoculated controls).

\section{Time course experiment, RNA extractions, and microarray hybridizations.}

For each genotype, 60 melon seedlings were inoculated with WMV-M116 and another 60 were mock inoculated. Cotyledons were harvested from 10 plants at 1, 3, 5, 7, 9, and 15 dpi. Harvested plants were removed from the assay after each harvest. At 15 dpi, the systemically infected second true leaf was also harvested. By this time, 'Tendral' second leaves showed evident mosaic and malformation symptoms, resembling those typically induced by WMV, whereas TGR-1551 plants were symptomless (Fig. 1). Samples were independently frozen in liquid $\mathrm{N}_{2}$ and stored at $-80^{\circ} \mathrm{C}$. RNA extracts were prepared using Tri-Reagent (Sigma-Aldrich, St. Louis) following the manufacturer's instructions. WMV infection was checked by dot-blot hybridization (Kassem et al. 2007) using $1 \mu \mathrm{g}$ of RNA extract. To reduce variability, each biological replicate was prepared by mixing the RNA extracts from two or four mockor WMV-inoculated cotyledons, respectively, or from three melon leaves. To eliminate traces of genomic DNA, total RNA was incubated with DNAse I (New England Biolabs, London) for $10 \mathrm{~min}$ at $37^{\circ} \mathrm{C}$. The reaction volume was adjusted to 100 $\mu \mathrm{l}$ and the aqueous phase extracted with phenol/chloroform/ isoamyl alcohol (125:24:1). Total RNA was precipitated with $10 \%$ ( $\mathrm{vol} / \mathrm{vol}) \mathrm{NaCl} 3 \mathrm{M}$ and 2.5 volumes of absolute ethanol by centrifugation $\left(12,000 \times \mathrm{g}, 20 \mathrm{~min}, 4^{\circ} \mathrm{C}\right)$. The quantity and quality of RNA were determined using a ND-1000 spectrophotometer (Nano Drop Technologies, Wilmington, DE, U.S.A.) and a Bioanalyzer (Agilent Technologies, Palo Alto, CA, U.S.A.). All samples were used for viral load quantification, and samples corresponding to 1,3, and 7 dpi were selected for microarray analysis and were sent for further processing at the NimbleGen microarray hybridization service (Roche NimbleGen Iceland LLC, Reykjavik, Iceland). Processing consisted of cDNA synthesis, Cy3 cDNA labeling, hybridization, scanning, and image reading. The data discussed in this publication have been deposited in the National Center for Biotechnology Information's GEO (Barrett et al. 2011) and are accessible through GEO Series accession number GSE30111.

\section{Real-time reverse-transcription qPCR.}

Real-time qPCR was carried out using an AB 7500 System (Applied Biosystems, Foster City, CA, U.S.A.), with Power SYBR green dye (Applied Biosystems) and ROX as a passive reference. CYCLOPHILIN mRNA was used as the endogenous control (Gonzalez-Ibeas et al. 2007), $\Delta \Delta$-cycle threshold was the algorithm for relative quantification, and three technical replicates were used for statistical analysis. Melting curve analysis at the reaction end-point and no-template controls were used to ensure product-specific amplification and to avoid primer-dimer quantification. A control reverse transcription without the enzyme was carried out to evaluate genomic DNA contamination. Primers to quantify the melon transcripts were designed using Primer Express (Applied Biosystems) or Primer3 (Rozen and Skaletsky 2000) from EST sequences in the Melogen database. Primers to quantify WMV-M116 RNA were designed using the virus sequence from GenBank (accession number AF551334).

\section{Data analysis.}

Data produced by the NimbleGen service were normalized using the RMA algorithm within oligo (vs. 1.8.2) (Carvalho et al. 2007) written in R (vs. 2.9.1) (R Project for Statistical Computing website). Density histograms and box-plot diagrams were generated using the same package and used to confirm that the data were efficiently normalized and the technical variability was acceptable for downstream analysis (Supplementary Fig. S4). Differentially expressed genes were identified using MaSigPro (v. 1.16.0) (Conesa et al. 2006) written in R, and the SAM module (Tusher et al. 2001) of the Multiexperiment viewer (MeV) (v. 4.4.1) program (Saeed et al. 2006). Clustering analysis was carried out using the $\mathrm{MeV}$ module Hierarchical Clustering Support Trees (ST) (Eisen et al. 1998). Biological variability was estimated using the MeV PCA module (Raychaudhuri et al. 2000). Over-represented GO (Ashburner et al. 2000) terms among the differentially expressed genes were identified using the FatiGO module (Al-Shahrour et al. 2007) in the Babelomics (v. 3) suite (Al-Shahrour et al. 2008). GO terms with an adjusted $P$ value $<0.1$ for multiple comparisons were considered statistically significant.

\section{ACKNOWLEDGMENTS}

This work was supported by grant AGL2009-07552/AGR from Ministerio de Ciencia e Innovación (Spain). We thank E. Moriones and $\mathrm{M}$ Gómez-Guillamón for providing materials for this work, M. C. Montesinos and B. Gosalvez for their technical assistance and R. M. Twyman for editorial assistance. 


\section{LITERATURE CITED}

Abdel-Ghany, S. E., and Pilon, M. 2008. MicroRNA-mediated systemic down-regulation of copper protein expression in response to low copper availability in Arabidopsis. J. Biol. Chem. 283:15932-15945.

Agudelo-Romero, P., Carbonell, P., Perez-Amador, M. A., and Elena, S. F. 2008. Virus adaptation by manipulation of host's gene expression. PLoS ONE 3:e2397. Published online.

Al-Shahrour, F., Minguez, P., Tárraga, J., Medina, I., Alloza, E., Montaner, D., and Dopazo, J. 2007. FatiGO+: A functional profiling tool for genomic data. Integration of functional annotation, regulatory motifs and interaction data with microarray experiments. Nucleic Acids Res. 35:W91-W96.

Al-Shahrour, F., Carbonell, J., Minguez, P., Goetz, S., Conesa, A., Tarraga, J., Medina, I., Alloza, E., Montaner, D., and Dopazo, J. 2008. Babelomics: Advanced functional profiling of transcriptomics, proteomics and genomics experiments. Nucleic Acids Res. 36:W341-W346.

Aranda, M. A., Escaler, M., Wang, D., and Maule, A. J. 1996. Induction of HSP70 and polyubiquitin expression associated with plant virus replication. Proc. Natl. Acad. Sci. U.S.A. 93:15289-15293.

Ashburner, M., Ball, C. A., Blake, J. A., Botstein, D., Butler, H., Cherry, J. M., Davis, A. P., Dolinski, K., Dwight, S. S., Eppig, J. T., Harris, M. A., Hill, D. P., Issel-Tarver, L., Kasarskis, A., Lewis, S., Matese, J. C., Richardson, J. E., Ringwald, M., Rubin, G. M., and Sherlock G. 2000. Gene ontology: Tool for the unification of biology. The Gene Ontology Consortium. Nat. Genet. 25:25-29.

Babu, M., Gagarinova, A. G., Brandle, J. E., and Wang, A. 2008. Association of the transcriptional response of soybean plants with Soybean mosaic virus systemic infection. J. Gen. Mol. Virol. 89:1069-1080.

Barrett, T., Troup, D. B., Wilhite, S. E., Ledoux, P., Evangelista, C., Kim, I. F., Tomashevsky, M., Marshall K. A., Phillippy, K. H., Sherman, P. M., Muertter, R. N., Holko, M., Ayanbule, O., Yefanov, A., and Soboleva, A. 2011. NCBI GEO: Archive for functional genomics data sets-10 years on. Nucleic Acids Res. 39:D1005-D1010.

Benschop, J. J., Mohammed, S., O'Flaherty, M., Heck, A. J. R., Slijper, M., and Menke, F. L. H. 2007. Quantitative phosphoproteomics of early elicitor signaling in Arabidopsis. Mol. Cell. Proteomics 6:1198-1214.

Büschges, R., Hollricher, K., Panstruga, R., Simons, G., Wolter, M., Frijters, A., van Daelen, R., van der Lee, T., Diergaarde, P., Groenendijk, J., Töpsch, S., Vos, P., Salamini, F., and Schulze-Lefert, P. 1997. The barley Mlo gene: A novel control element of plant pathogen resistance. Cell 88:695-705.

Carroll, A. J., Heazlewood, J. L., Ito, J., and Millar, A. H. 2008. Analysis of the Arabidopsis cytosolic ribosome proteome provides detailed insights into its components and their post-translational modification. Mol. Cell. Proteomics 7:347-369.

Carvalho, B., Bengtsson, H., Speed, T. P., and Irizarry, R. A. 2007. Exploration, normalization, and genotype calls of high-density oligonucleotide SNP array data. Biostatistics 8:485-499.

Catoni, M., Miozzi, L., Fiorilli, V., Lanfranco, L., and Accotto, G. P. 2009. Comparative analysis of expression profiles in shoots and roots of tomato systemically infected by Tomato spotted wilt virus reveals organspecific transcriptional responses. Mol. Plant-Microbe Interact. 22:1504-1513.

Chandra-Shekara, A. C., Venugopal, S. C., Barman, S. R., Kachroo, A., and Kachroo, P. 2007. Plastidial fatty acid levels regulate resistance gene-dependent defense signaling in Arabidopsis. Proc. Natl. Acad. Sci. U.S.A. 104:7277-7282.

Clepet, C., Joobeur, T., Zheng, Y., Jublot, D., Huang, M., Truniger, V., Boualem, A., Hernandez-Gonzalez, M. E., Dolcet-Sanjuan, R., Portnoy, V., Mascarell-Creus, A., Cano-Delgado, A. I., Katzir, N., Bendahmane, A., Giovannoni, J. J., Aranda, M. A., Garcia-Mas, J., and Fei, Z. 2011. Analysis of expressed sequence tags generated from full-length enriched cDNA libraries of melon. BMC Genomics 12:252.

Conesa, A., Nueda, M. J., Ferrer, A., and Talon, M. 2006. maSigPro: A method to identify significantly differential expression profiles in time-course microarray experiments. Bioinformatics 22:1096-1102.

Dardick, C. 2007. Comparative expression profiling of Nicotiana benthamiana leaves systemically infected with three fruit tree viruses. Mol. Plant-Microbe Interact. 20:1004-1017.

Diaz-Pendon, J. A., Fernandez-Munoz, R., Gomez-Guillamon, M. L., and Moriones, E. 2005. Inheritance of resistance to Watermelon mosaic virus in Cucumis melo that impairs virus accumulation, symptom expression, and aphid transmission. Phytopathology 95:840-846.

Doudna, J. A., and Rath, V. L. 2002. Structure and function of the eukaryotic ribosome: The next frontier. Cell 109:153-156.

Dudoit, S., Gentleman, R. C., and Quackenbush, J. 2003. Open source software for the analysis of microarray data. BioTechniques Suppl.:45-51.
Eisen, M. B., Spellman, P. T., Brown, P. O., and Botstein, D. 1998. Cluster analysis and display of genome-wide expression patterns. Proc. Natl. Acad. Sci. U.S.A. 95:14863-14868.

Espinoza, C., Vega, A., Medina, C., Schlauch, K., Cramer, G., and ArceJohnson, P. 2007. Gene expression associated with compatible viral diseases in grapevine cultivars. Funct. Integr. Genomics 7:95-110.

Fraser, R. S. S. 1992. The genetics of plant-virus interactions: Implications for plant breeding. Euphytica 63:175-185.

Gammelgård, E. 2007. Interactions of Potato virus A with host plants. Thesis. Swedish University of Agricultural Sciences, Uppsala, Sweden.

Gandía, M., Conesa, A., Ancillo, G., Gadea, J., Forment, J., Pallás, V., Flores, R., Duran-Vila, N., Moreno, P., and Guerri, J. 2007. Transcriptional response of Citrus aurantifolia to infection by Citrus tristeza virus. Virology 367:298-306.

García-Marcos, A., Pacheco, R., Martiáñez, J., González-Jara, P., DíazRuíz, J. R., and Tenllado, F. 2009. Transcriptional changes and oxidative stress associated with the synergistic interaction between Potato virus $X$ and Potato virus $Y$ and their relationship with symptom expression. Mol. Plant-Microbe Interact. 22:1431-1444.

Golem, S., and Culver, J. N. 2003. Tobacco mosaic virus induced alterations in the gene expression profile of Arabidopsis thaliana. Mol. Plant-Microbe Interact. 16:681-688.

Gonzalez-Ibeas, D., Blanca, J., Roig, C., Gonzalez-To, M., Pico, B., Truniger, V., Gomez, P., Deleu, W., Cano-Delgado, A., Arus, P., Nuez, F., Garcia-Mas, J., Puigdomenech, P., and Aranda, M. 2007. MELOGEN: An EST database for melon functional genomics. BMC Genomics 8:306.

Gonzalez-Ibeas, D., Blanca, J., Donaire, L., Saladié, M., Mascarell-Creus, A., Cano-Delgado, A., Garcia-Mas, J., Llave, C., and Aranda, M. A. 2011. Analysis of the melon (Cucumis melo) small RNAome by highthroughput pyrosequencing. BMC Genomics 12:393.

Ishibashi, K., Masuda, K., Naito, S., Meshi, T., and Ishikawa, M. 2007. An inhibitor of viral RNA replication is encoded by a plant resistance gene. Proc. Natl. Acad. Sci. U.S.A. 104:13833-13838.

Kang, B.-C., Yeam, I., and Jahn, M. M. 2005. Genetics of plant virus resistance. Annu. Rev. Phytopathol. 43:581-621.

Kassem, M. A., Sempere, R. N., Juarez, M., Aranda, M. A., and Truniger, V. 2007. Cucurbit aphid-borne yellows virus is prevalent in fieldgrown cucurbit crops of southeastern Spain. Plant Dis. 91:232-238.

Lee, M.-L. T. 2004. Analysis of Microarray Gene Expression Data. Kluwer Academic Publishers, Boston.

Madlung, A., and Comai, L. 2004. The effect of stress on genome regulation and structure. Ann. Bot. 94:481-495.

Marathe, R., Guan, Z., Anandalakshmi, R., Zhao, H., and Dinesh-Kumar, S. P. 2004. Study of Arabidopsis thaliana resistome in response to Cucumber mosaic virus infection using whole genome microarray. Plant Mol. Biol. 55:501-520.

Mascarell-Creus, A., Cañizares, J., Vilarrasa-Blasi, J., Mora-García, S., Blanca, J., Gonzalez-Ibeas, D., Saladié, M., Roig, C., Deleu, W., PicóSilvent, B., López-Bigas, N., Aranda, M. A., Garcia-Mas, J., Nuez, F., Puigdomènech, P., and Cano-Delgado, A. I. 2009. An oligo-based microarray offers novel transcriptomic approaches for the analysis of pathogen resistance and fruit quality traits in melon (Cucumis melo L.). BMC Genomics 10:467-467.

Maule, A., Leh, V., and Lederer, C. 2002. The dialogue between viruses and hosts in compatible interactions. Curr. Opin. Plant Biol. 5:279-284.

Nicaise, V., German-Retana, S., Sanjuan, R., Dubrana, M.-P., Mazier, M., Maisonneuve, B., Candresse, T., Caranta, C., and LeGall, O. 2003. The eukaryotic translation initiation factor 4E controls lettuce Susceptibility to the potyvirus Lettuce mosaic virus. Plant Physiol. 132:1272-1282.

Nieto, C., Morales, M., Orjeda, G., Clepet, C., Monfort, A., Sturbois, B., Puigdomènech, P., Pitrat, M., Caboche, M., Dogimont, C., GarciaMas, J., Aranda, M. A., and Bendahmane, A. 2006. An eIF4E allele confers resistance to an uncapped and non-polyadenylated RNA virus in melon. Plant J. 48:452-462.

Nieto, C., Piron, F., Dalmais, M., Marco, C. F., Moriones, E., GómezGuillamón, M. L., Truniger, V., Gómez, P., Garcia-Mas, J., Aranda, M. A., and Bendahmane, A. 2007. EcoTILLING for the identification of allelic variants of melon eIF4E, a factor that controls virus susceptibility. BMC Plant Biol. 7:34-34.

Page, G. P., and Coulibaly, I. 2008. Bioinformatic tools for inferring functional information from plant microarray data: Tools for the first steps. Int. J. Plant Genomics 2008:147563-147563.

Palukaitis, P., and Carr, J. P. 2008. Plant resistance responses to viruses. J. Plant Pathol. 90:153-171.

Park, T., Yi, S.-G., Lee, S., Lee, S. Y., Yoo, D.-H., Ahn, J.-I., and Lee, Y.-S. 2003. Statistical tests for identifying differentially expressed genes in time-course microarray experiments. Bioinformatics 19:694-703.

Pompe-Novak, M., Gruden, K., Baebler, S., Krecic-Stres, H., Kovac, M., 
Jongsma, M., and Ravnikar, M. 2005. Potato virus $Y$ induced changes in the gene expression of potato (Solanum tuberosum L.). Physiol. Mol. Plant Pathol. 67:237-247.

Raffaele, S., Vailleau, F., Leger, A., Joubes, J., Miersch, O., Huard, C., Blee, E., Mongrand, S., Domergue, F., and Roby, D. 2008. A MYB transcription factor regulates very-long-chain fatty acid biosynthesis for activation of the hypersensitive cell death response in Arabidopsis. Plant Cell 20:752-767.

Raychaudhuri, S., Stuart, J. M., and Altman, R. B. 2000. Principal components analysis to summarize microarray experiments: Application to sporulation time series. Pac. Symp. Biocomput. 2000:455-466.

Revers, F., Lot, H., Souche, S., Le Gall, O., Candresse, T., and Dunez, J. 1997. Biological and molecular variability of Lettuce mosaic virus isolates. Phytopathology 87:397-403.

Robaglia, C., and Caranta, C. 2006. Translation initiation factors: A weak link in plant RNA virus infection. Trends Plant Sci. 11:40-45.

Rozen, S., and Skaletsky, H. J. 2000. Primer3 on the WWW for general users and for biologist programmers. Pages 365-386 in: Bioinformatics Methods and Protocols, Methods in Molecular Biology. S. Krawetz and S. Misener, eds. Humana Press, Totowa, NJ, U.S.A.

Saeed, A. I., Bhagabati, N. K., Braisted, J. C., Liang, W., Sharov, V., Howe, E. A., Li, J., Thiagarajan, M., White, J. A., and Quackenbush, J. 2006. TM4 microarray software suite. Methods Enzymol. 411:134-193.

Satoh, K., Kondoh, H., Sasaya, T., Shimizu, T., Choi, I.-R., Omura, T., and Kikuchi, S. 2010. Selective modification of rice (Oryza sativa) gene expression by Rice stripe virus infection. J. Gen. Virol. 91:294-305.

Sekine, K.-T., Nandi, A., Ishihara, T., Hase, S., Ikegami, M., Shah, J., and Takahashi, H. 2004. Enhanced resistance to Cucumber mosaic virus in the Arabidopsis thaliana ssi2 mutant is mediated via an SA-independent mechanism. Mol. Plant-Microbe Interact. 17:623-632.

Senthil, G., Liu, H., Puram, V. G., Clark, A., Stromberg, A., and Goodin, M. M. 2005. Specific and common changes in Nicotiana benthamiana gene expression in response to infection by enveloped viruses. J. Gen. Virol. 86:2615-2625.

Shi, C., Ingvardsen, C., Thümmler, F., Melchinger, A. E., Wenzel, G., and Lübberstedt, T. 2005. Identification by suppression subtractive hybridization of genes that are differentially expressed between nearisogenic maize lines in association with Sugarcane mosaic virus resistance. Mol. Genet. Genomics 273:450-461.

Smith, C. M., Rodriguez-Buey, M., Karlsson, J., and Campbell, M. M.
2004. The response of the poplar transcriptome to wounding and subsequent infection by a viral pathogen. New Phytol. 164:123-136.

Soria, C., Moriones, E., Fereres, A., Garzo, E., and Gómez-Guillamón, M.L. 2003. New source of resistance to mosaic virus transmission by Aphis gossypii in melon. Euphytica 133:313-318.

Truniger, V., and Aranda, M. A. 2009. Recessive resistance to plant viruses. Adv. Virus Res. 75:119-159.

Truniger, V., Nieto, C., González-Ibeas, D., and Aranda, M. 2008. Mechanism of plant eIF4E-mediated resistance against a Carmovirus (Tombusviridae): Cap-independent translation of a viral RNA controlled in cis by an (a)virulence determinant. Plant J. 56:716-727.

Tusher, V. G., Tibshirani, R., and Chu, G. 2001. Significance analysis of microarrays applied to the ionizing radiation response. Proc. Natl. Acad. Sci. U.S.A. 98:5116-5121.

Vaucheret, H., Mallory, A. C., and Bartel, D. P. 2006. AGO1 homeostasis entails coexpression of MIR168 and AGO1 and preferential stabilization of miR168 by AGO1. Mol. Cell 22:129-136.

Wang, D., and Maule, A. J. 1995. Inhibition of host gene expression associated with plant virus replication. Science 267:229-231.

Whitham, S. A., Quan, S., Chang, H.-S., Cooper, B., Estes, B., Zhu, T., Wang, X., and Hou, Y.-M. 2003. Diverse RNA viruses elicit the expression of common sets of genes in susceptible Arabidopsis thaliana plants. Plant J. 33:271-283.

Whitham, S. A., Yang, C., and Goodin, M. M. 2006. Global impact: Elucidating plant responses to viral infection. Mol. Plant-Microbe Interact. 19:1207-1215.

Yang, C., Guo, R., Jie, F., Nettleton, D., Peng, J., Carr, T., Yeakley, J. M., Fan, J.-B., and Whitham, S. A. 2007. Spatial analysis of Arabidopsis thaliana gene expression in response to Turnip mosaic virus infection. Mol. Plant-Microbe Interact. 20:358-370.

Yang, C., Zhang, C., Dittman, J. D., and Whitham, S. A. 2009. Differential requirement of ribosomal protein S6 by plant RNA viruses with different translation initiation strategies. Virology 390:163-173.

\section{AUTHOR-RECOMMENDED INTERNET RESOURCE}

NCBI GEO series accession number GSE30111 page: www.ncbi.nlm.nih.gov/geo/query/acc.cgi?acc=GSE30111

R Project for Statistical Computing: www.R-project.org 